\title{
Expulsion from Community Childcare Centers During the COVID-19 Pandemic: A Review of One State's Practices
}

\author{
Keri Giordano ${ }^{1}\left[\right.$ D Eileen McKeating ${ }^{2} \cdot$ Debbie Chung $^{1} \cdot$ Victoria Garcia $^{1}$
}

Accepted: 14 January 2022 / Published online: 31 January 2022

(c) The Author(s), under exclusive licence to Springer Nature B.V. 2022

\begin{abstract}
Expulsion has been a well-documented practice in early learning centers throughout the United States. The present study attempted to describe expulsion practices in one state's community childcare centers during the COVID-19 pandemic. Surveys from 161 childcare program administrators were analyzed and, overall, expulsion rates appeared to be lower than they were pre-pandemic. No association was found between whether a program closed and reopened or remained open; the presence of a waiting list; if a program readmitted all or some children; factors that influenced which teachers were rehired; training provided to teaching staff; perceived frequency and intensity of challenging behavior; and availability of support for children with challenging behaviors and expulsion decisions. Results of the current study are analyzed and discussed in this article along with the results and how they fit into the literature.
\end{abstract}

Keywords Early childhood $\cdot$ Expulsion $\cdot$ Community childcare centers $\cdot$ COVID-19

Exclusionary discipline from early care and education (ECE) settings throughout the United States has received public interest in recent years. Gilliam first highlighted the issue in 2005 when he reported that early childhood expulsion occurred at a rate three times higher than with school-age children (Gilliam, 2005). Research indicates that exclusionary discipline is a predictor of negative future educational and social-emotional outcomes (Noltemeyer et al., 2015), including decreased math and reading achievement (Lacoe \& Steinberg, 2018), disengagement from school, diminished educational opportunity (Skiba et al., 2014), and incarceration (Barnes \& Motz, 2018). When the COVID-19 pandemic hit the United States, childcare centers were affected in various ways, ranging from programs being forced to close and, for those that reopened, operating with reduced class sizes and other health requirements and constraints. What is unknown is how these changes impacted expulsion practices. Therefore, the current study examined expulsion from childcare centers during the first year of the COVID-19

Keri Giordano

KGiordan@kean.edu

1 Kean University, 1000 Morris Avenue, Union, NJ 07083, USA

2 Montclair State University, Montclair, NJ, USA pandemic in one state in the northeast region of the United States community.

\section{Early Childhood Expulsion}

Preschool expulsion first received mainstream attention in the United States in 2005 following Walter Gilliam's landmark study (Gilliam, 2005) and remained a critical issue in ECE settings (U.S., 2014). Expulsion is defined as the permanent removal of a child from an educational setting due to a violation of school policies (School Discipline Support Initiative, 2020). ECE expulsions affect young children disproportionately. For example, the pattern of expulsion among African American students that is evident from kindergarten to 12th grade appears to begin earlier in ECE settings (Gilliam, 2005; Giordano, Interra, et al., 2021). Exclusionary discipline of a preschool child is a strong predictor of future negative educational and social-emotional outcomes. Children who experience early expulsion are more likely to encounter future academic failure, hold negative school attitudes, drop out of school, and be involved in the juvenile justice system (American Academy of Pediatrics Committee on School Health, 2013).

When children are expelled, they are separated from the educational process and any support services available to 
them in the educational setting. While at home, the child may not have adequate supervision or support, especially if the primary caregiver works full time (Zinsser, et al., 2019). If caregivers are forced to take time off or leave their jobs in order to care for their child as a result of sudden expulsion, this can also have significant financial implications for the family (Southward, et al., 2006). Additionally, children may miss out on the time needed to develop valuable foundational learning skills. Since ECE attendance is not a requirement by law, if expelled, children are not entitled to educational alternatives (Loomis et al., 2021).

In addition to the learning and financial impacts, there is no evidence that suggests that expulsion decreases challenging behaviors. Instead, children remain at home without behavioral supports until they are enrolled in a new ECE setting, where they enter with no change in their behavioral patterns or skill set, thus remaining at risk of being expelled again. Therefore, the practice of expulsion actually conflicts with already established knowledge that supports children's social-emotional wellbeing (Loomis et al., 2021). Evidence suggests that outcomes for young children can improve with interventions, such as the implementation of Early Childhood Mental Health Consultation (ECMHC) (Hepburn et al., 2013), which results in a reduction of children's challenging behaviors and improvements in their prosocial behaviors (Perry et al., 2010) and thus increasing the likelihood that they will successfully remain in learning settings.

\section{Factors that Effect Expulsion}

It is important to focus on all of the contextual factors that contribute to ECE's disciplinary practices in order to most effectively address the high rates of expulsion in these settings. In addition to more systemic factors, such as unclear policies and lack of funding (Loomis et al., 2021), the effects of teachers' and administrators' perceptions of child behaviors also must be taken into account to most fully understand and address this issue. Research has found that child expulsion is not typically the result of a singular incident, but rather due to a series of events culminating in an ultimatum made to the parents (Martin et al., 2018). Researchers have explored common reasons that lead to students' expulsions and found that disruptive classroom behaviors and the concern that a child may pose a risk of injury to self or others are principal reasons for considering a preschool expulsion (Gilliam \& Reyes, 2018; Giordano, Vega, et al., 2021). Children who present with more behavior challenges are more likely to be expelled (Feil et al., 2014; Hemmeter et al., 2007). Childcare center directors frequently report behavioral problems and the safety of other children as the two main reasons for expelling a child (Bee, 2012; Giordano, Vega, et al., 2021). In addition to child behaviors, parental behaviors (e.g., parents exhibiting "problem behaviors") and failing to pay tuition have also been cited as reasons for expulsion (Giordano, Vega, et al., 2021).

\section{Child \& Family Characteristics}

Child and family characteristics, particularly demographic background, have also been a factor of expulsion. Racial disproportionality is found across age ranges and settings among children who are expelled (Loomis et al., 2021). According to the U.S. Department of Education data in 2011, expulsion rates categorized by race presented as $6 \%$ for Latino, $33 \%$ for Black students, and $2 \%$ for White students. This discrepancy among expulsion rates by race could be explained by implicit bias, unconscious beliefs, or attitudes we hold. A study has shown that adults, when viewing a Black child's face as young as five years old are more likely to perceive a threat of aggression (Todd et al., 2016). This finding suggests that the higher preschool expulsion rates seen among Black preschoolers could potentially be attributed to the Black preschoolers likely seen as presenting a potential risk for harm (e.g., another child being injured, a threat to staff well-being, teacher accountability) (Gilliam \& Reyes, 2018). In line with this finding, Gilliam (2005) found that Black preschoolers were about twice as likely to be expelled as European-American (both Latino and non-Latino) and five times as likely as Asian-American preschoolers. Compared to students of other racial backgrounds, Black/African American students were over three times as likely to be expelled. Hispanic/Latino/Spanish children were found to have a relative risk for expulsion twice as high as their peers, while White students were less likely to be expelled than all other races.

In addition to students' racial background, other factors play a role in the discrepancy in expulsion rates. Gender is one such factor. The study has found that boys were expelled at a rate over 4.5 times that of girls (Gilliam, 2005); for Black students, boys accounted for $91.4 \%$ of the expulsions. Age was also a factor in expulsion decisions; older preschoolers were expelled at a higher rate relative to younger preschoolers. Four-year-olds were expelled at a rate about $50 \%$ greater than either 2-year-olds or 3-year-olds. Children who were either 5 or 6 years old were about twice as likely to be expelled than 4-year-olds. (Gilliam, 2005). Research in elementary and secondary exclusionary-discipline practices has identified significant exclusionary discipline disparities for students with disabilities (Achilles et al., 2007; Losen et al., 2015; Miller \& Meyers, 2015). As ECE teachers have reported using expulsion as a disciplinary practice at alarming rates in general (Gilliam \& Shahar, 2006), the increased prevalence of exclusionary practices for students with disabilities in the older grades (U.S., 2014) makes one wonder if these young children are being expelled for early signs of an 
unidentified disability. Children with disabilities or socialemotional difficulties have been found to be 14.5 times more likely to be expelled than their typically developing peers (Novoa \& Malik, 2018). Specifically, young children with ADHD were at a higher risk of being suspended or expelled than children with other disabilities. Children with ADHD may also have higher exclusionary discipline rates due to early childhood programs lacking available resources, such as consultants or specialists, to help them meet the needs of children at all levels of behavioral and academic abilities.

\section{Teacher Qualities \& Teacher Training}

Early childhood expulsion is also connected to various elements of a teacher's social-emotional wellbeing. Early childhood teachers report experiencing more stress than their non-teaching peers that stems from a lack of resources, feeling underappreciated, and working long hours for low rates of pay. Teachers who request expulsions may link their experience of stress to an individual child's behavior or having to balance the needs of a child against those of the rest of the class (Zinsser, et al., 2019). Ultimately, in ECE settings, teachers' reports of child behavior are the main source of information used to make expulsion decisions (Silver \& Zinsser, 2020).

A teacher's sense of hopelessness may also contribute to an increased likelihood of preschool expulsions. Statefunded prekindergarten teachers with depressive symptoms report nearly twice the rate of expulsions compared with those who did not screen positive for depression, suggesting that expulsion may pose as a more feasible option for teachers when children's challenging behaviors become too stressful, or lead to feelings of hopelessness for potential behavioral improvement (Gilliam, 2005). Although teacher depression and job stress were examined as predictors of expulsion rates in general, the study did not examine the relationship between depression, stress, and perceptions regarding specific children's challenging behaviors. Researchers developed the Preschool Expulsion Risk Measure (PERM) to assess the propensity to be expelled and found that preschool expulsions may be contingent upon the teacher's perceptions of the child's behaviors in terms of the degree to which a child's behaviors: (a) become classroom disruptions and (b) pose a risk of injury and lead to teacher accountability. Also, these expulsions may relate to more global issues of the degree to which these behaviors may lead the teacher to: (c) feel hopeless that little can be done to improve the challenging behaviors (d) and experience heightened teacher stress (Gilliam \& Reyes, 2018).

Teachers' education levels, such as whether the teachers held bachelor's degrees in early education, the number of hours of operation for the program, and teachers' pedagogical beliefs and practices, have not been found to be correlated with either expulsion or suspension (Gilliam \& Shahar, 2006). However, depressive symptoms and teacher job stress correlated significantly to whether a teacher expelled a child in the past 12 months. Job stress and a poor sense of job satisfaction may impact teachers' relationship with children or their perceptions of children's behavioral problems, resulting in an increased reliance on expulsion (Gilliam \& Shahar, 2006). This further suggests that expulsion is related more to teacher factors than child behaviors.

Another study examined preschool and child care expulsion and suspension in a randomly selected sample of Massachusetts preschool teachers during a 12-month period (Gilliam \& Shahar, 2006). Findings showed that larger classes, a higher proportion of 3 year-olds in the class, and elevated teacher job stress predicted an increased likelihood of expulsion. When teachers are placed with high demands to maintain an orderly classroom setting with larger group sizes and a higher proportion of children on the younger end of the preschool-age spectrum, these demands often result in an increased reliance on expulsion to manage classroom behavior. An in-depth qualitative analysis of 30 childcare providers found that teachers define children's behavior leading up to expulsion as increasingly dangerous, especially towards other children (Martin et al., 2018). Further, as teachers conflicted with parents' approaches to these problems, teachers' accounts suggested that they began to see the problem not residing in the child but in the 'home environment.' Teachers would begin to construct narratives about "bad parenting and families." Thus, the children's challenging behaviors became redefined as unfixable. Schools would shift the blame from the child to the parent. When childcare providers attributed the problem as one that extended beyond the childcare domain, they would decide on expulsion as a solution, as they deemed the problem as something beyond their ability to intervene (Martin et al., 2018).

\section{Availability of Support}

Giordano, Vega, et al. (2021) found that the majority educators in these programs (those that suspended and expelled children and those that did not) did not feel that they had the resources they needed to support children with challenging behaviors. Availability of support may be one factor that leads to feelings of helplessness experienced by teachers and program directors prior to expulsion. Prekindergarten expulsion rates were found to be related significantly to teacher access to classroom-based mental health consultation (Gilliam, 2005). A study that examined data collected as part of the National Prekindergarten Study (NPS), consisting of classroom-level data from all 52 state-funded prekindergarten systems operating in the United States during the 2003 and 2004 academic years, found that the percentage of prekindergarten teachers reported to have expelled at least one 
child in the past 12 months is significantly lower at each level of increased access to classroom-based mental health consultation provided by either a psychologist/psychiatrist. When teachers reported having access to a mental health consultant that provided classroom-based strategies for dealing with challenging student behaviors, the likelihood of expulsion was lower. Having access to a mental health consultant who could come to the classroom in response to a request initiated by the teacher was better than no access at all. However, the lowest expulsion rates were reported by teachers who had an ongoing, regular relationship with a mental health consultant - either because the teacher and consultant shared a building or because the consultant paid regular visits to the classroom at least monthly. From these data, it is not possible to know whether access to a mental health consultant caused the decreased likelihood of expulsion or if other factors, such as a greater overall level of resources in programs where consultants are made available, were responsible. However, given the rather pronounced differences in expulsion rates when mental health consultants are available to teachers, the effectiveness of consultancybased systems of support to preschool teachers deserves further consideration.

\section{COVID-19 Pandemic}

\section{COVID-19 and Stress}

Adverse Childhood Experiences (ACEs), defined by various forms of abuse, neglect, and household dysfunction, have been a major public health problem in the United States; the COVID-19 pandemic may have amplified some ACEs, exacerbated by school closures, social isolation, parental stressors, loss, and other stressors as a result of the pandemic (Sanders, 2020). The pandemic may have increased intrafamilial adversity, and thus exposing children to increased parental anxieties, particularly those associated with job loss, food insecurity, and housing insecurity. Preschool children who are exposed to ACEs are more likely to experience expulsion. Exposure to cumulative stress can negatively affect children's behavior at school (Ridout et al., 2018) as children are more likely to have difficulty developing executive functioning skills such as self-regulation skills, which may result in more challenging behaviors (Zeng et al., 2019). Further, children with high levels of exposure to adversity have been found to be associated with higher rates of disabilities (McLaughlin et al., 2012), behavior disorders (Hunt et al., 2017), anxiety, and depression (Rose et al., 2014), which has been suggested to lead to an increase of the likelihood of preschool expulsion and suspension.

As preschool is a critical time in which children are introduced to school, supporting young children's social-emotional development has become an essential responsibility of early childhood educators. Teachers have reported feeling unprepared to support children with challenging behavior (Martin et al., 2018). Further, teachers may also not be familiar with how adverse experiences in early childhood impacts the lives of students and their families.

Ironically, children who have experienced ACEs and other traumas may need additional support as they may also lack family well-being as a strong predictor of their school readiness (Duncan et al., 2007). Overall, expulsion and suspension deny children who are more vulnerable access to meaningful early intervention for their disabilities or mental health issues (American Academy of Pediatrics Committee on School Health, 2013).

\section{COVID-19 in Our State}

In the state in the northeastern United States where this study was conducted, in March of 2020, in response to cases of COVID-19, executive orders were issued that closed childcare centers, with the exception of those providing childcare to children of essential workers. During this time, childcare was funded for essential workers through Executive Order 110 (2020), where programs were paid a set stipend weekly per enrolled child. After approximately three months of closure, in June 2020, all childcare centers were permitted to reopen. Health and safety requirements, including temperature checks, distancing requirements, limits of 10 or fewer children in a group with no mixing of groups, mask wearing rules, and regulations prohibited the sharing of toys and materials were put into place (Exec. Order No. 149, 2020). In November 2020, approximately eight months after program closures and five months after general childcare reopening, we collected the data for our study.

\section{The Present Study}

Given the impact that COVID-19 has had on all aspects of life, the present study aims to examine the expulsion practices in one state's community childcare centers during the first year of the pandemic. More specifically, descriptions of whether a program closed and reopened or remained open; the presence of a waiting list; if a program readmitted all or some children; factors that influenced which teachers were rehired; training provided to teaching staff; perceived frequency and intensity of challenging behavior; and availability of support for children with challenging behaviors are provided. Additionally, these factors are examined to determine their association with expulsion decisions. Finally, we compare expulsion practices during COVID to practices prior to the pandemic. 


\section{Method}

\section{Procedures}

After obtaining IRB approval, researchers accessed a published list of all licensed early childhood programs in the state; programs listed as public schools or only providing services to children ages six years and older were removed, leaving 3013 centers. A recruitment email with a link to an online survey was sent to these programs approximately eight months after the state initiated its first lockdown requirements; of these, 511 emails were undeliverable, resulting in surveys being sent to 2502 programs. It is unknown how many of these programs were operating during this time. The recruitment email invited participants to complete a 10-minute online survey describing challenging behaviors and expulsion practices during the COVID-19 pandemic and remained open for a two-week time period.

\section{Participants}

Responses were received from 194 program administrators; all counties in the state were represented. Given that it is unknown how many programs were open during the time of the survey administration, it is difficult to determine a response rate, but the survey had a $90.6 \%$ completion rate. Participants who reported that their programs were still closed or operating in remote format only, who did not identify as community childcare, or did not respond to the question asking if they had expelled a child during the pandemic were excluded, leaving 161 surveys remaining for analysis.

\section{Measures}

For this study, the authors developed a multiple-choice online survey aimed at gathering information regarding expulsion practices during the COVID-19 pandemic. Participants were permitted to skip questions, and the average time to complete the survey was 7 minutes and 39 seconds. The survey asked questions about how the COVID-19 pandemic impacted the program, including whether or not the program closed, if they maintained a waiting list, factors they considered when re-admitting children and rehiring teachers, and information on training that was provided to staff. The survey also asked about challenging behavior, including if there was a change in the frequency and intensity of behavior, whether or not they have expelled children during the pandemic, and what the reason for the expulsion was. Finally, participants were asked if they have support available if they encounter children who display challenging behavior.

\section{Results}

The majority of participants $(83.9 \% ; n=135)$ indicated that their programs had closed at some point during the pandemic. Most did not have an active waiting list (73.9\%; $n=119)$. When reopening, some participants $(18.0 \%$; $n=29)$ readmitted all of the children who were enrolled in the program prior to the pandemic. Approximately onethird $(28.6 \% ; n=46)$ had all staff return. For programs that did not have all staff return $(n=115)$, the majority $(53.9 \%$; $n=62$ ) reported that it was because the staff member chose not to return. For other programs, it was a mutual decision $(38.2 \% ; n=44)$, while fewer participants reported it being an administrator decision $(7.8 \% ; n=9)$. When asked the primary factor that was considered in deciding whether or not to rehire teaching staff, most participants $(61.5 \% ; n=99)$ described logistical considerations (i.e., the staff member's health and personal needs; flexibility; longevity; and salary). The remaining participants $(37.3 \% ; n=60)$ selected factors related to quality (i.e., quality of their relationships with children and families; quality of their teaching; classroom management skills) as their primary reason; two participants did not provide factors. In regards to training provided to staff prior to reopening, a slight majority $(54.0 \% ; n=87)$ reported providing training related to social-emotional needs (e.g., trauma, challenging behaviors, social-emotional learning).

When asked about expulsion during the pandemic, 17.4\% $(n=28)$ of respondents indicated that they had expelled at least one child. The majority $(60.7 \% ; n=17)$ reported expelling one child, followed by expelling two children (17.9\%; $n=5)$. Only one program expelled 3 and 4 children $(3.6 \%$ each), and four programs indicated that they did expel at least one child but did not specify how many. Thus, at least 34 children were reported expelled during the COVID-19 pandemic across the 116 responding programs. Participants who reported an expulsion were asked to select the reason (see Table 1). They were provided with a list of options and asked to select all that apply; only two participants selected one reason. The most commonly reported reasons were displaying challenging behaviors that did not respond to typical discipline practices $(67.9 \% ; n=19)$ and hurting others $(64.2 \% ; n=18)$. The least frequently reported reasons included failure to adhere to COVID-19 rules and protocols and parental failure to complete required forms, each with one respondent (3.6\%). It is noted that only two participants indicated that a child was expelled exclusively for reasons related to parental behaviors.

Many reported that they did not see a change in either intensity $(47.2 \% ; n=76)$ or frequency $(44.7 \% ; n=72)$ of challenging behavior compared to a similar time of year prior to the pandemic, while some felt that the frequency 
Table 1 Reason cited for child expulsion from programs

\begin{tabular}{lcc}
\hline Reason & $N=28$ & $\%^{*}$ \\
\hline Displaying challenging behaviors that did not respond to typical discipline techniques & 19 & 67.9 \\
Hurting others & 18 & 64.3 \\
At risk for hurting self & 13 & 46.4 \\
Has special needs the program did not have resources to support & 11 & 39.2 \\
Uncontrollable temper tantrums & 11 & 39.2 \\
Failed to adjust to program after a reasonable amount of time & 11 & 39.2 \\
Not a good match for program & 6 & 21.4 \\
Parent displayed "problem behavior" (ex: does not adhere to policies, verbally or physi- & 4 & 14.3 \\
$\quad$ cally threatens staff, etc.) & 4 & 14.3 \\
Parent failed to pay tuition & 1 & 3.6 \\
Lack of adherence to COVID-19 procedures & 1 & 3.6 \\
Failure to complete forms and paperwork(ex: medical documentation, updated applica- \\
$\quad$ tion paperwork, etc.)
\end{tabular}

*Percentages total greater than 100 as participants were permitted to select more than one response
Table 2 Sources of support when faced with a child with challenging behavior

\begin{tabular}{llr}
\hline Source & $N=104$ & $\%$ \\
\hline Local public school, early intervention & 23 & 22.1 \\
Consultant, coach, TA provider & 17 & 16.3 \\
Administrator, supervisor & 17 & 16.3 \\
State or county level child-family support office & 11 & 10.6 \\
External mental health professional & 10 & 9.6 \\
Child's pediatrician & 7 & 6.7 \\
Child's parents & 6 & 5.8 \\
Colleagues & 6 & 5.8 \\
Town health nurse/ local health department & 6 & 5.8 \\
State office of licensing & 5 & 4.8 \\
Priest & 1 & 1.0 \\
\hline
\end{tabular}

*Percentages total greater than 100 as participants were permitted to select more than one response

$(36.0 \% ; n=58)$ and intensity $(32.9 \% ; n=53)$ of challenging behaviors was less. Participants were less likely to feel that the frequency $(19.3 \% ; n=31)$ and intensity $(19.9 \% ; n=32)$ of challenging behaviors were more. The majority of participants $(64.6 \% ; n=104)$ indicated that they had someone to support them if children in their programs began displaying challenging behavior or signs of trauma (See Table 2). Frequently reported sources of support included local public school or early intervention providers $(22.1 \% ; n=23)$, a program consultant, coach or Technical Assistance (TA) provider $(16.3 \% ; n=17)$, and a program administrator or supervisor $(16.3 \% ; n=17)$.

In order to examine the association between these factors and the decision to expel, a series of binary logistic regressions were run with expulsion status (yes or no) as the outcome variable. The following factors were predictor variables: reopening status (remained open or reopened); waiting list (yes or no); child readmission decisions (all or some); frequency of challenging behavior (more, same, less); the intensity of challenging behavior (more, same, less); teacher rehire decision (quality or logistic); socialemotional training provided (yes or no); support available for challenging behavior (yes or no). Binary logistical regression is a statistic used to predict the relationship between a predictor variable and an outcome variable, when the outcome variable is dichotomous. Pairwise deletion was utilized, removing participants who did not respond to the question regarding the factor under examination from the analysis. Results indicate that none of the variables significantly predicted expulsion (see Table 3 ).

\section{Discussion}

This study aimed to describe expulsion practices in community childcare centers during the COVID-19 pandemic. Research conducted in this state prior to the pandemic indicated that approximately $36 \%$ of responding centers had expelled a child in the past twelve months (Giordano, Vega, et al., 2021). In this prior research, 196 children were expelled across 368 programs, representing a rate of 0.53 children per program. In the current study, $17.4 \%$ of responding programs expelled at least one child, with 34 children reported being expelled across 161 programs, showing a rate of 0.21 children per program. Although these are not direct comparison groups, it seems as if there may be an overall decrease in expulsion during the pandemic.

Results of this study surprised us in that according to the current study data, expulsions seem as if they may have decreased during the pandemic. Interestingly, none of the factors we examined predicted expulsion. The data 
Table 3 Binomial regression results predicting expulsion

\begin{tabular}{|c|c|c|c|c|c|}
\hline \multirow[t]{2}{*}{ Factor } & \multirow[t]{2}{*}{$\beta$} & \multirow[t]{2}{*}{$\operatorname{Exp}(B)$} & \multicolumn{2}{|l|}{$95 \% \mathrm{CI}$} & \multirow[t]{2}{*}{$p$} \\
\hline & & & Lower & Upper & \\
\hline \multicolumn{6}{|l|}{ Reopened or stayed open } \\
\hline Reopened & 0.148 & 1.159 & 0.396 & 3.392 & 0.787 \\
\hline \multicolumn{6}{|l|}{ Has waitlist } \\
\hline Yes, waitlist & 0.040 & 1.041 & 0.407 & 2.665 & 0.934 \\
\hline \multicolumn{6}{|l|}{ Child Readmit } \\
\hline Some & -0.028 & 0.972 & 0.333 & 2.842 & 0.959 \\
\hline Behavior frequency & & & & & 0.363 \\
\hline More & -0.223 & 0.800 & 0.303 & 2.111 & 0.652 \\
\hline Same & 0.553 & 1.739 & 0.630 & 4.802 & 0.286 \\
\hline Behavior intensity & & & & & 0.152 \\
\hline More & -0.480 & 0.619 & 0.219 & 1.748 & 0.365 \\
\hline Same & 0.640 & 1.896 & 0.715 & 5.027 & 0.198 \\
\hline \multicolumn{6}{|l|}{ All staff returned } \\
\hline Yes & 0.230 & 1.258 & 0.495 & 3.200 & 0.630 \\
\hline \multicolumn{6}{|l|}{ Teacher rehire factors } \\
\hline Quality & -.0324 & .0723 & 0.313 & 1.671 & 0.448 \\
\hline \multicolumn{6}{|l|}{ Training type provided } \\
\hline SEL/behavior/trauma & 0.741 & 2.097 & 0.912 & 4.826 & 0.081 \\
\hline \multicolumn{6}{|l|}{ Support available } \\
\hline Yes & 0.739 & 2.093 & 0.917 & 4.777 & 0.079 \\
\hline
\end{tabular}

concluded that most programs were forced to close for a time period and did not maintain a waiting list. As childcare is a business that is already operating with slim profit margins, these closures, combined with reduced capacities, were financially devastating to many programs. In our state, $32 \%$ of providers reported that they could not financially survive any closure, while 59\% stated they could not survive more than a month (Advocates for the Children of New Jersey, 2020). In this case, perhaps the decrease in expulsions is a result of the increased financial need of centers? It was also revealed that the majority of administrators invited all their teaching staff back. In fact, only a very small percentage (7.8\%) of administrators indicated that the decision not to bring a staff member back was theirs. We were surprised by this result and expected that more administrators would use this to retain quality staff and allow other staff to move on. Do these results mean that administrators found their teaching staff to be high quality and genuinely wanted to rehire them all? Or was this more because programs were given relatively short notice that they could reopen, and it was quicker and easier to simply bring back all of those employed before out of necessity? Given that most administrators reported considering logistical factors rather than those related to the quality of teaching, it seems as if more information is needed regarding the forces driving these decisions to be able to look at their impacts authentically.
When it comes to reasons behind expulsion, in line with prior research (Giordano, Vega, et al., 2021), hurting other children and displaying challenging behavior remain highly cited reasons for expulsion. It is noted that only approximately $20 \%$ of participants in the current study indicated that challenging behavior was worse in intensity and frequency than it was prior to the pandemic. Most indicated that it stayed the same or was less frequent and intense than before the pandemic. This was also a result that we did not expect, as we thought, in line with Zinsser et al. (2019), that administrators experiencing high levels of stress themselves would be less able to meet the needs of their students'. This combined with children returning to care after being at home for a period of time, unused to newly instituted classroom routines and rules, made us believe that participants might experience and report an increase in intensity and frequency of challenging behaviors. Our results made us wonder if there was a change in perception triggered by the pandemic. Perhaps childcare center staff were so grateful to be back at work that they were able to take a more positive view? Possibly the children were pleased to be back in their centers, reunited with their teachers and other children? Or maybe the time off allowed for much-needed self-care that allowed staff to return to work in a place more ready to meet the needs of students? Perhaps the gravity of the situation or information received in professional development training provided during closure caused them to become more tolerant of challenging behaviors during this adjustment?

Alternatively, there were many structural changes that took place that also may have lessened challenging behaviors. For example, reduced class sizes may have allowed for more individualized attention, ameliorating incidences that may result in children becoming stressed or acting out. In addition, when programs reopened, they did so with requirements to keep children separate and not to allow them to share materials. The enforcement of social distancing and cleaning procedures meant children were not permitted to share small spaces or toys, conditions which naturally result in contentious interactions between young children. Centers sometimes prepared individual packets of materials (e.g., play-doh, art supplies) and stored them in children's cubbies for personal use. The physical separation of children and fewer opportunities for sharing toys and materials may have impacted teachers' perceptions and reporting of less or the same intensity and frequency of behaviors that they find challenging. Physical proximity and navigating sharing of materials are often antecedents for challenging behaviors, so the reduction of these triggers, combined with fewer children in the room overall, may have resulted in an actual decrease in challenging behaviors. While this decrease is desired, this natural conflict regarding the negotiation of materials and space is developmentally required for the acquisition of 
social-emotional competencies (i.e., sharing, turn-taking, problem-solving). Without these experiences, although expulsions might decrease, going forward, children might face additional challenges in navigating social interactions with peers.

Interestingly, parental reasons for expulsion (failure to pay tuition and parents displaying "problem behavior") were frequently cited as reasons for expulsion prior to the pandemic (Giordano, Vega, et al., 2021), yet were reported much less frequently as reasons during the pandemic. In fact, expulsions for reasons related to parental behaviors were the least cited explanations in our study. So, again, we have to wonder if pandemic experiences have resulted in a change in parental behavior. It may be that parents, who were often spread very thin during childcare closures, were so relieved that programs were reopening that they were more sensitive to the requirements of their child attending care. Alternatively, maybe a recognition and appreciation of childcare providers as essential workers caused a shift in parent behavior. Or, as previously discussed, it could be that a shift in the provider's stress level caused them to become more tolerant during these early stages of reopening. Finally, the financial aspect must also be considered, where centers are relying on tuition payments to stay afloat and may have been able to work around more parent behavior in order to keep the child successfully enrolled.

We wish to discuss a final point that revolves around the availability of support when program staff faces a child who displays extreme challenging behavior. Research has shown that when programs have access to mental health professionals, they can better meet children's social and emotional needs (Gilliam, 2005; Hepburn et al., 2013; Perry et al., 2010). Prior to the pandemic, research (Giordano, Vega, et al., 2021) indicated that the majority of community childcare programs (73\%) did not have the resources needed to support children with challenging behavior. During the pandemic, the majority of programs (64.6\%) indicated that they did have such supports. Again, while this is a positive trend, more information is needed to understand the cause of this shift fully. Maybe it is that the pandemic has called for an increased awareness of mental health, and the availability of resources has increased? Or have services become more accessible with telehealth options being available by many providers? Perhaps the above-described shift in challenging behaviors has allowed programs to feel supported with less intensive support (e.g., coach, administrative support)? There is also the issue of differing opinions and possible misunderstanding of what constitutes mental health support in ECE. Although the question about having support was a dichotomous choice (yes/no), the question asking who provides that support was open-ended. If participants were given options to select from, they may have reflected more deeply and reported not having support available. The problem may lie in disparate definitions of support between researchers and practitioners.

Although this survey provides valuable insight into expulsion practices during the first year of the COVID-19 pandemic, it is not without limitations. The survey was a closed ended survey, forcing participants to select from a list, rather than an open-ended survey which would have allowed for more elaboration of responses. Additionally, survey items were open to the interpretation of the respondent, so some may have determined a behavior to fall under one reason, while another provider may have placed the same behavior under another reason for expulsion. The survey was only sent to providers in one state, and it was sent during a time when many providers may have been feeling overwhelmed with their reopening process. Within that state, it is unknown which providers were operating and which remained closed. Given these restrictions, it is impossible to determine if these results represent the childcare population as a whole. Additionally, these results represent the experiences of childcare centers from one state under one way of responding to the pandemic; providers in other states with different rules and regulations may have different experiences entirely. Centers with limited resources most likely are not represented, as they most likely remained closed due to financial issues and constraints, and operating restrictions.

This speaks to the need for future work to continue to examine the shift in expulsion practices over time, as vaccines become available for young children, new variants arise, and more parents are returning to their traditional work settings. Results also suggest no predictive relationship between the factors being examined and expulsion status. Therefore, future research should also consider the additional factors described throughout our discussion as potential predictors of expulsion. Research into the disparate definitions between researchers and practitioners of mental health support is also an area for further examination. Finally, in this study, we did not ask about the demographics of children who were expelled. While it is important to know how expulsion practices are disproportionately impacting certain populations during the pandemic, we made the decision to utilize a simpler survey with the hopes that this would encourage our already stressed and overworked administrators to participate. Future work is needed to more thoroughly examine how the pandemic has impacted, and continues to impact, expulsion for those who were previously at higher risk.

\section{Conclusions}

Overall, results from this study indicate a positive trend of decreasing expulsion numbers during the first year of COVID-19 pandemic. Clearly, the pandemic brought a 
whole new set of challenges to an already under-resourced private childcare industry. The stress of these challenges and generalized pandemic-related worries, one might surmise, could have resulted in increased expulsions and suspensions of children in ECE settings. However, the rate of expulsion appears to have decreased and, although the downward trend is a positive outcome, we must further understand the forces driving this change to help ensure a lasting effect. While we entered this project believing that certain factors would impact a change in expulsion rates, our results indicate that these factors did not account for the shift we are seeing. Rather, we postulate that other COVID-related factors may have been in play during the study's time span. In general, society seemed to develop a newfound appreciation for essential workers, including the child care workforce. This appreciation may have resulted in families being more sensitive and tolerant towards staff. Financial considerations may have also necessitated a certain measure of tolerance by programs operating under severe financial constraints due to lowered enrollments and safety regulations. The most surprising finding was that survey participants reported the same or fewer rates in the frequency and intensity of difficult behavior, despite the lapse of attendance, disruption of routines, and increased levels of stress that occurred during the pandemic. In summary, this survey seemed to prompt more questions than answers. This research has shown that expulsion practices and beliefs are ever-changing, and as we enter the "new normal" of COVID-19 living, we must continue to examine how uncertainty and evolving circumstances impact expulsion practices in the childcare community.

\section{References}

Achilles, G. M., Mclaughlin, M. J., \& Croninger, R. G. (2007). Sociocultural correlates of disciplinary exclusion among students with emotional, behavioral, and learning disabilities in the SEELS national dataset. Journal of Emotional and Behavioral Disorders, 15(1), 33-45. https://doi.org/10.1177/10634266070150010401

Advocates for the Children of New Jersey. (2020). COVID-19 and the New Jersey child care system: Surveying its impact on those most affected. https://legacy.earlysuccess.org/sites/default/files/COVID 19surveydocument.pdf.

American Academy of Pediatrics Committee on School Health. (2013). Out-of-school suspension and expulsion. Pediatrics, 131(3), 1206-1209. https://doi.org/10.1542/peds.2012-3932

Barnes, J. C., \& Motz, R. T. (2018). Reducing racial inequalities in adulthood arrest by reducing inequalities in school discipline: Evidence from the school-to-prison pipeline. Developmental Psychology, 54(12), 2328-2340. https://doi.org/10.1037/dev0000613

Bee, D. (2012). An exploratory study of child care center directors' response to young children's challenging behaviors and the impact on preschool expulsion (Unpublished doctoral dissertation). Florida State University.

Duncan, G. J., Dowsett, C. J., Claessens, A., Magnuson, K., Huston, A. C., Klebanov, P., Pagani, L. S., Feinstein, L., Engel, M., Brooks-Gunn, J., Sexton, H., Duckworth, K., \& Japel, C.
(2007). School readiness and later achievement. Developmental Psychology, 43(6), 1428-1446. https://doi.org/10.1037/00121649.43.6.1428

Exec. Order No. 149. 52 N.J.R. 1297(a). (2020).

Exec. Order No. 110. 52 N.J.R. 828(a). (2020).

Feil, E. G., Frey, A., Walker, H. M., Small, J. W., Seeley, J. R., Golly, A., \& Forness, S. R. (2014). The efficacy of a home-school intervention for preschoolers with challenging behaviors. Journal of Early Intervention, 36(3), 151-170. https://doi.org/10.1177/10538 15114566090

Gilliam, W. S. (2005). Prekindergarteners left behind: Expulsion rates in state prekindergarten systems. Yale University Child Study Center. https://www.fcd-us.org/assets/2016/04/ExpulsionComple teReport.pdf.

Gilliam, W. S., \& Reyes, C. R. (2018). Teacher decision factors that lead to preschool expulsion. Infants \& Young Children, 31(2), 93-108. https://doi.org/10.1097/iyc.0000000000000113

Gilliam, W. S., \& Shahar, G. (2006). Preschool and child care expulsion and suspension. Infants \& Young Children, 19(3), 228-245. https://doi.org/10.1097/00001163-200607000-00007

Giordano, K., Interra, V., Stillo, G., Mims, A., \& Block-Lerner, J. (2021). Associations between child and administrator race and suspension and expulsion rates in community child care programs. Early Childhood Education Journal, 49, 125-135. https://doi.org/ 10.1007/s10643-020-01049-1

Giordano, K., Vega, V., \& Gubi, A. (2021). Expelled from childcare: One state's suspension \& expulsion practices in community childcare centers. Early Childhood Education Journal. https://doi.org/ 10.1007/s10643-020-01134-5

Hemmeter, M. L., Fox, L., Jack, S., \& Broyles, L. (2007). A programwide model of positive behavior support in early childhood settings. Journal of Early Intervention, 29(4), 337-355. https://doi. org/10.1177/105381510702900405

Hepburn, K. S., Perry, D., Shivers, E. M., \& Gilliam, W. (2013). Early childhood mental health consultation as an evidence-based practice. Zero to Three, 33(5), 10-19.

Hunt, T. K. A., Slack, K. S., \& Berger, L. M. (2017). Adverse childhood experiences and behavioral problems in Middle Childhood. Child Abuse \& Neglect, 67, 391-402. https://doi.org/10.1016/j. chiabu.2016.11.005

School Discipline Support Initiative. (2020). Expulsion. https://suppo rtiveschooldiscipline.org/expulsion.

Lacoe, J., \& Steinberg, M. P. (2018). Do suspensions affect student outcomes? Educational Evaluation and Policy Analysis, 41(1), 34-62. https://doi.org/10.3102/0162373718794897

Loomis, A., Davis, A., Cruden, G., Padilla, C., \& Drazen, Y. (2021). Early childhood suspension and expulsion: A content analysis of state legislation. Early Childhood Education Journal. https://doi. org/10.1007/s10643-021-01159-4

Losen, D. J., Ee, J., Hodson, C., \& Martinez, T. (2015). Disturbing inequities: Exploring the relationship between racial disparities in special education identification and discipline. In D. J. Losen (Ed.), Closing the School Discipline Gap: Equitable Remedies for Excessive Exclusion. New York: Teachers College Press.

Martin, K. A., Bosk, E., \& Bailey, D. (2018). Teachers' perceptions of childcare and preschool expulsion. Children \& Society, 32(2), 87-97. https://doi.org/10.1111/chso.12228

McLaughlin, K. A., Greif Green, J., Gruber, M. J., Sampson, N. A., Zaslavsky, A. M., \& Kessler, R. C. (2012). Childhood adversities and first onset of psychiatric disorders in a national sample of US adolescents. Archives of General Psychiatry, 69(11), 1151. https:// doi.org/10.1001/archgenpsychiatry.2011.2277

Miller, C. E., \& Meyers, S. A. (2015). Disparities in school discipline practices for students with emotional and learning disabilities and autism. Journal of Education and Human Development. https:// doi.org/10.15640/jehd.v4n1a23 
Noltemeyer, A. L., Ward, R. M., \& Mcloughlin, C. (2015). Relationship between school suspension and student outcomes: A metaanalysis. School Psychology Review, 44(2), 224-240.

Novoa, C., \& Malik, R. (2018). Suspensions are not support: The disciplining of preschoolers with disabilities. https://www.americanpr ogress.org/issues/early-childhood/reports/2018/01/17/445041/ suspensions-not-support/\#: :text=Children\%20with\%20disabili ties $\% 20$ face $\% 20$ higher $\% 20$ odds $\% 20$ of $\% 20$ being $\% 20$ expelled\& text $=$ The $\% 20$ odds $\% 20$ of $\% 20$ being $\% 20$ suspended $\% 20$ or $\% 20$ exp elled $\% 20$ were $\% 20$ more $\% 20$ than,higher $\% 20$ for $\% 20$ children $\%$ 20with\%20ADHD.

Perry, D. F., Allen, M. D., Brennan, E. M., \& Bradley, J. R. (2010). The evidence base for mental health consultation in early childhood settings: A research synthesis addressing children's behavioral outcomes. Early Education \& Development, 21(6), 795-824. https://doi.org/10.1080/10409280903475444

Ridout, K. K., Khan, M., \& Ridout, S. J. (2018). Adverse childhood experiences run deep: Toxic early life stress, telomeres, and mitochondrial DNA copy number, the biological markers of cumulative stress. BioEssays, 40(9), 1800077. https://doi.org/10.1002/ bies. 201800077

Rose, S. M. S. F., Xie, D., \& Stineman, M. (2014). Adverse childhood experiences and disability in US adults. $P M \& R, 6(8), 670-680$.

Sanders, L. M. (2020). Is covid-19 an adverse childhood experience (ACE): Implications for screening for primary care. The Journal of Pediatrics, 222, 4-6. https://doi.org/10.1016/j.jpeds.2020.05. 064

Silver, H. C., \& Zinsser, K. M. (2020). The interplay among early childhood teachers' social and emotional well-being, mental health consultation, and preschool expulsion. Early Education and Development, 31(7), 1133-1150. https://doi.org/10.1080/10409 289.2020.1785267
Skiba, R. J., Arredondo, M. I., \& Williams, N. T. (2014). More than a metaphor: The contribution of exclusionary discipline to a schoolto-prison pipeline. Equity \& Excellence in Education, 47(4), 546564. https://doi.org/10.1080/10665684.2014.958965

Southward, L. H., Blanchard, T., Costello, H., Hanna, H., \& Buffum, L. (2006). Economic volatility and expulsion in U.S. child care settings: A multi-state survey. Mississippi State University, Social Science Research Center; Center for Child Health Research. http:// www.ssrc.msstate.edu/wp-content/uploads/fcru_nf_cb_0206a.pdf.

Todd, A. R., Thiem, K. C., \& Neel, R. (2016). Does seeing faces of young Black boys facilitate the identification of threatening stimuli? Psychological Science, 27(3), 384-393. https://doi.org/10. $1177 / 0956797615624492$

U.S. Department of Health and Human Services, \& U.S Department of Education (2014). Policy statement on expulsion and suspension policies in early childhood settings. https://www.zerotothree.org/ document/78.

Zeng, S., Corr, C. P., O’Grady, C., \& Guan, Y. (2019). Adverse childhood experiences and preschool suspension expulsion: A population study. Child Abuse \& Neglect. https://doi.org/10.1016/j. chiabu.2019.104149

Zinsser, K. M., Zulauf, C. A., Nair Das, V., \& Callie Silver, H. (2019). Utilizing social-emotional learning supports to address teacher stress and preschool expulsion. Journal of Applied Developmental Psychology, 61, 33-42. https://doi.org/10.1016/j.appdev.2017.11. 006

Publisher's Note Springer Nature remains neutral with regard to jurisdictional claims in published maps and institutional affiliations. 